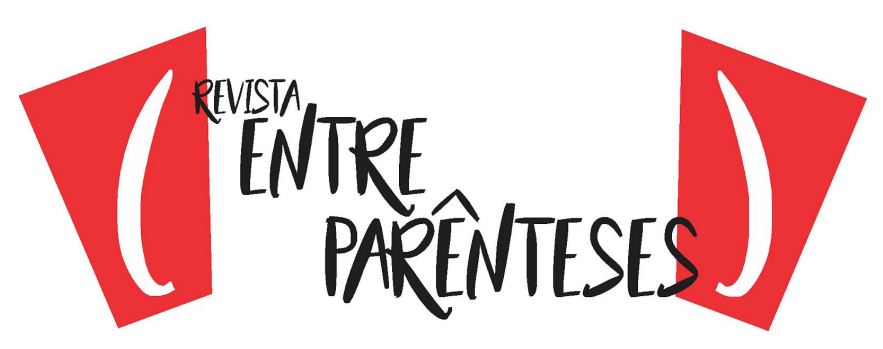

\title{
A (RE)CONSTRUÇÃO DA PERSONAGEM HISTÓRICA MARTINA CHAPANAY (1800-1874) NO CONTO “EL MAESTRO Y LA REINA DE LAS AMAZONAS” (2001), DE MARÍA ROSA LOJO
}

\author{
Adriana Aparecida Biancato ${ }^{1}$ \\ Universidade Estadual do Oeste do Paraná - UNIOESTE - PR \\ (adri@nrecascavel.com) \\ Gilmei Francisco Fleck ${ }^{2}$ \\ Universidade Estadual do Oeste do Paraná - UNIOESTE - PR \\ (chicofleck@yahoo.com.br)
}

\begin{abstract}
Resumo: María Rosa Lojo (1954), escritora argentina contemporânea, é uma das ficcionistas que considera relevante a relação entre história e ficção e aspecto essencial no processo literário hispano-americano. Isso se evidencia não só em seus romances, mas, também, nos contos de Amores Insólitos de Nuestra Historia (2001), que se configuram como narrativas de extração histórica, (TROUCHE, 2006). Sob esta perspectiva, pretendemos analisar a (re)construção da personagem histórica, a guerrilheira Martina Chapanay (1800-1874), que atuou nas guerras civis argentinas durante o século XIX, ficcionalizada no conto "El Maestro y la Reina de las Amazonas". Tal personagem representa a figura feminina, cujas ações são invisibilizadas no discurso oficial, e que subvertem o discurso patriarcal. Para este estudo os fundamentos teóricos de Aínsa (1991), Esteves (2011) Fleck (2011; 2017), Fernández Prieto (2003), entre outros, serão apoio à análise efetuada. Por meio desta leitura crítica do texto híbrido em pauta evidenciamos as intenções de revelar outras perspectivas sobre o passado exposto nos anais da história, porém ressignificado na ficção.
\end{abstract}

Palavras-chave: História e Ficção; Amores insólitos de nuestra historia (2001); Conto Hispano-americano contemporâneo; Personagem de extração histórica; Literatura Argentina.

\begin{abstract}
María Rosa Lojo (1954), a contemporary Argentine writer, is one of the fiction writers who considers the relationship between history and fiction as a relevant and essential aspect of the Spanish-American literary process. This is highlighted not only in her novels, but also in her collection of short-stories, Amores insólitos de nuestra historia (2001), which are taken as historical extraction narratives, (TROUCHE, 2006). Under this perspective, we intend to analyze the (re) construction of the historical character of the guerrilla Martina Chapanay (1800-1874), who worked for the Argentine civil wars during the nineteenth century, fictionalized in the story "The Master and Queen of the Amazons." Such a character represents the female figure, whose actions are invisible in the official discourse and subvert the patriarchal discourse. For this study, the theoretical foundations of Aínsa (1991), Esteves (2011) Fleck (2011; 2017), Fernández Prieto (2003), among others, will support the analysis that has been carried out. Through this critical reading of the hybrid text, we aim at revealing

\footnotetext{
${ }^{1}$ Mestranda em Letras, Universidade Estadual do Oeste do Paraná, adri@nrecascavel.com.

2 Professor Associado da UNIOESTE/Cascavel-PR/Brasil na Graduação em Letras, nas áreas de Literatura e Cultura Hispânicas, na Pós-graduação em Letras (Mestrado Acadêmico e Doutorado) nas áreas de Literatura Comparada e Tradução e no Mestrado Profissional - Profletras - Cascavel/PR na área da Literatura Infanto-juvenil. Pós-doutor em Literatura Comparada e Tradução pela UVigo/Espanha, com bolsa da CAPES. Doutor e Mestre em Letras pela UNESP/Assis. Coordenador do PELCA: Programa de Ensino de Literatura e Cultura. Coordenador do Projeto de Pesquisa "Ressignificações do passado na América Latina: leitura, escrita e tradução de gêneros híbridos de história e ficção - vias para a descolonização". E-mail: chicofleck@yahoo.com.br
} 


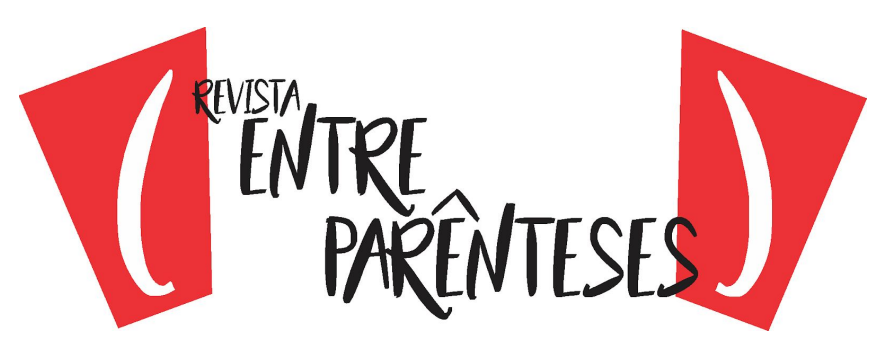

other perspectives on the past, exposed at the annals of history, however, been re-signified in fiction. Keywords: History and Fiction; Amores insólitos de nuestra historia (2001); Contemporary Hispanic-American tale; Character of historical extraction; Literature Argentina.

Resumen: María Rosa Lojo (1954), escritora argentina contemporánea, es una de las ficcionistas que considera relevante la relación entre historia y ficción y aspecto esencial en el proceso literario hispanoamericano. Esto se evidencia no sólo en sus novelas, sino también en los cuentos de Amores Insólitos de Nuestra Historia (2001), que se configuran como narrativas de extracción histórica, (TROUCHE, 2006). En esta perspectiva, pretendemos analizar la (re) construcción del personaje histórico de la guerrilla Martina Chapanay (1800-1874), que actuó en las guerras civiles argentinas durante el siglo XIX, ficcionalizada en el cuento "El Maestro y la Reina de las Amazonas". Tal personaje representa la figura femenina, cuyas acciones son invisibilizadas en el discurso oficial, y que subvierten el discurso patriarcal. Para este estudio los fundamentos teóricos de Aínsa (1991), Esteves (2011) Fleck (2011; 2017), Fernández Prieto (2003), entre otros, serán apoyo al análisis efectuado. Por medio de esta lectura crítica del texto híbrido en pauta evidenciamos las intenciones de revelar otras perspectivas sobre el pasado expuesto en los anales de la historia, pero resignificado en la ficción.

Palabras clave: Historia y Ficción; Amores insólitos de nuestra historia (2001); Cuento Hispanoamericano contemporáneo; Personaje de extracción histórica; Literatura Argentina.

María Rosa Lojo, como herdeira do exílio de seus pais galegos, nasceu na Argentina, nação latino-americana que os acolheu, como o fez com muitos outros. Ao longo dos anos, tornou-se Doutora em Letras pela Universidade de Buenos Aires e hoje é, também, romancista, poetisa, crítica literária e pesquisadora reconhecida internacionalmente pela expressão de sua obra narrativa, poética e teórica, tendo já parte de sua obra traduzida a vários idiomas em diferentes países.

Como escritora argentina contemporânea, é uma das ficcionistas latino-americanas que considera a relação entre história e ficção essencial ao processo literário dos países antes colonizados. Desse modo, relata em seus textos, muitas vezes autobiográficos, o quanto a "Guerra Civil Espanhola" que levou seus progenitores ao "Novo Mundo", sempre esteve presente em seu desenvolvimento e educação. Essas são questões identitárias que a escritora manifesta em sua obra por meio das antinomias de vozes e culturas que se entrelaçam, reflexo da dualidade de construção identitária que é transposta no seu discurso literário. Em 


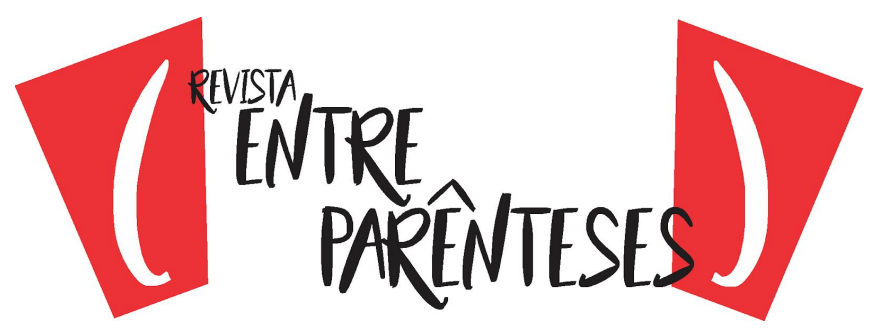

sua "Mínima autobiografía de una 'exiliada hija" (2006), Lojo descreve o sentimento de não pertença aquele continente, língua e identidade:

Quien [...] acaso piense que el peso de la identidad heredada podía llegar a volverse, para los hijos del exilio, un tanto asfixiante. No le faltará razón. Durante mucho tiempo, casi hasta la mayoría de edad, sentí mi permanencia en la Argentina como una estadía transitoria. El momento del regreso era, no sólo inminente sino decisivo: de él dependía la orientación entera de la vida, la trama de los deseos. Ese acontecimiento, tan postergado como próximo, hacía que todo pareciera incompleto y provisorio. (LOJO, 2006, p. 7).

A escrita híbrida proposta por María Rosa Lojo entrelaça dados da história, artifícios da ficção e aspectos da memória coletiva argentina num texto fluído e verossímil no qual emergem, das sombras do esquecimento, figuras inusitadas e carismáticas. Nessa tarefa de autora disposta a produzir narrativas de extração histórica (TROUCHE, 2006), ela 'costura', com elementos ficcionais próprios da prosa contemporânea, os dados historiográficos que, sob um tratamento literário minucioso, são revigorados e, de forma plausível e articulada, ressignificam muitos dos aspectos enunciados no discurso histórico assertivo do passado. Tais ressignificações literárias evidenciam aspectos omitidos, ignorados ou apenas superficialmente expostos com relação aos eventos ocorridos e os protagonistas que os executaram.

Confirma-se, na narrativa híbrida de Lojo, que, a partir dessas perspectivas postas às margens pelo discurso historiográfico, produzem-se, na América Latina, conforme defende Aínsa (1991, p. 82), obras híbridas nas quais se revela a necessidade do sujeito latino-americano de aprofundar-se em sua própria história, incorporando o imaginário individual e coletivo do passado à ficção.

Vemos, ainda, na obra da escritora contemporânea que

[...] este abandono de la historiografía moderna, legitimadora de un único relato sobre la historia se realiza con la disensión, el 


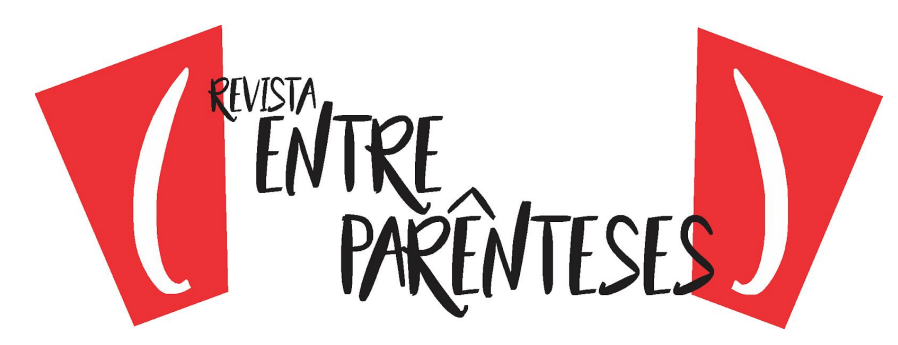

redescubrimiento, la humanización que trascienda a tales personajes de la historia inmortal a la que parecían condenados sin rescate. La nueva novela histórica los rescata y les otorga la existencia imaginativa, el diálogo, la humanidad que el relato de legitimación nacional o latinoamericano les negó para encubrir el pasado histórico de una retórica maniquea de buenos y malos, de héroes $y$ antihéroes, de grandes y pequeños hombres. La novela histórica los recupera en una multitud de relatos [...]. (LARIOS, 1997, p. 134).

Assim, nos vários romances históricos - e também nos contos híbridos de história e ficção - da professora, pesquisadora e escritora María Rosa Lojo, o passado que trata da conquista do território e da povoação da Argentina no século XIX é revisitado com intenções de evidenciar a importância que tiveram nesses eventos determinadas personagens, ou mesmo parcelas da população, invisibilizadas pelo discurso histórico que consagrou certas versões desse período no imaginário nacional.

Nas narrativas híbridas de Lojo, as personagens históricas são ficcionalizadas e tal processo thes assegura a humanização necessária que thes permite a possibilidade de contar uma "outra" história, sob uma perspectiva diferente daquela exposta na historiografia hegemônica oficial. Nesse processo escritural, María Rosa faz sua opção por essa via da "humanização" dos grandes heróis nacionais e pela "evidenciação de vozes silenciadas" com relação àquelas personagens marginalizadas nos discursos oficiais.

Nesse sentido, sua produção diferencia-se das narrativas híbridas de história e ficção intensamente cultivadas pelos escritores latino-americanos no período do boom latino-americano e -, dentro dele, no ápice da modalidade do novo romance histórico - protagonizadas por escritores como Alejo Carpentier, Augusto Roa Bastos, Carlos Fuentes, Abel Posse, Mário Vargas Llosa, entre outros. Essa primeira fase crítica da escrita híbrida de história e ficção na América Latina é caracterizada, principalmente, de acordo com Fleck (2017), pelo amplo experimentalismo formal e linguístico pelo qual a produção latino-americana crítica e 


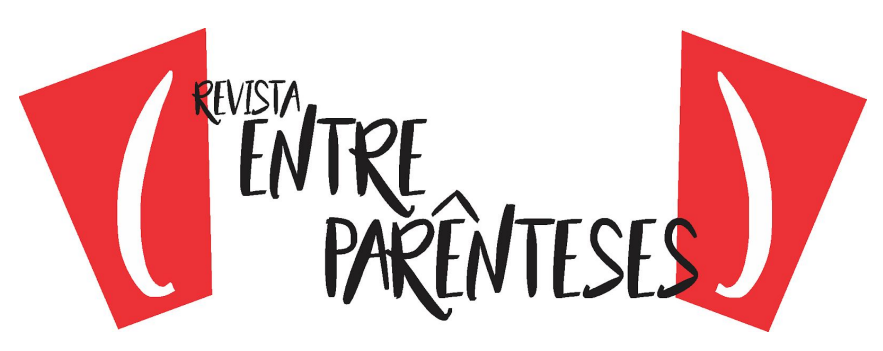

desconstrucionista se enfrentou, num primeiro momento, com o tradicionalismo exaltador de heróis da típica escrita híbrida literária acrítica instaurada na Europa no século XIX, por Walter Scott, e, em certos espaços e tempos, também praticada na América.

A reação dos escritores latino-americanos frente à acriticidade da escrita do romance histórico romântico clássico scottiano, e também daquela da modalidade tradicional que derivou do primeiro, é consequência, em parte, do lócus enunciativo próprio do sujeito latino-americano que se expressa, conforme definiu Silviano Santiago (2000), no "entre-lugar":

Entre o sacrifício e o jogo, entre a prisão e transgressão, entre a submissão ao código e a agressão, entre a obediência e a rebelião, entre a assimilação e a expressão - ali, nesse lugar aparentemente vazio, seu templo e seu lugar de clandestinidade, ali, se realiza o ritual antropófago da literatura latino-americana. (SANTIAGO, 2000, p. 26).

Lojo, por meio de suas manifestações literárias, cumpre com a função do artista latino-americano que, por meio do processo criativo, deseja fundar uma territorialidade, apropriando-se dos espaços simbólicos que a rodeiam para reterritorializar-se no espaço cultural, político e linguístico argentino atual. Isso se dá por meio da expressão de uma estética memorialista que revisa as "versões reducionistas" do passado para, então, ressignificá-las, impregnando-as das ideologias contemporâneas.

Isso instaura em sua obra uma espécie de anacronismo típico do fazer literário crítico atual que lança olhares sobre a causa - o passado - com vistas às consequências - o presente. Desse modo, sua produção se encontra dentro do que Fleck (2017) denomina como a terceira e atual fase das escritas híbridas de história e ficção: a fase mediativa - modalidade que descreve como uma tentativa de conciliação entre aquelas que a antecedem, pois, na sua elaboração, não se 


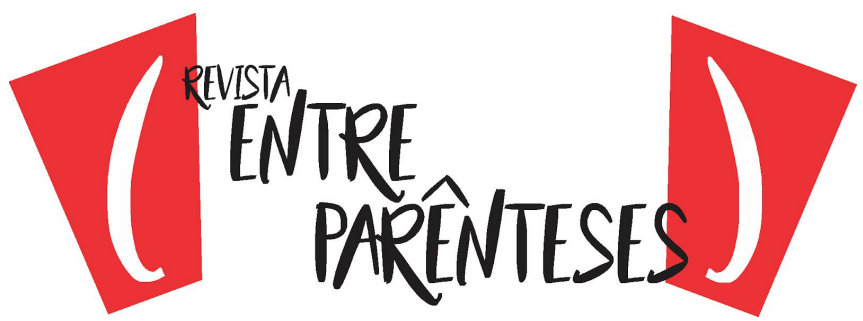

desprezam as características essenciais do novo romance histórico latino-americano, no entanto, tais narrativas apresentam uma diegese mais linear e nelas se modera o uso dos recursos mais desconstrucionistas presentes nos textos experimentalistas, o que confere mais acessibilidade à leitura dessas obras a um público mais amplo.

Dessa maneira, María Rosa recupera a memória coletiva do passado registrada, em especial, na escrita masculina da história - e, nesse espaço do "entre-lugar" que ainda cabe à literatura latino-americana, ressignifica-o. Isso ocorre por meio de um viés que valoriza em suas obras o olhar feminino a respeito do passado. Suas escritas híbridas revelam uma nova ótica da história das Américas, pois elas lançam um novo olhar sobre as personagens femininas representativas dessa história. São escritas que, sobretudo, concedem um lócus enunciativo àqueles que não foram considerados pela história. Entre tais personagens há relevância às amantes, às criadas, às indígenas, às mestiças, às cativas, cujas ações foram essenciais para os desfechos ocorridos.

Isso se evidencia não só em seus romances, mas, também, nos contos de Amores Insólitos de Nuestra Historia (2001), que se configuram como narrativas de extração histórica, segundo a denominação de André Trouche (2006, p. 43), que menciona esse como sendo o termo adequado aos textos híbridos, uma vez que ele representa as diversas modalidades dos relatos que mantém o diálogo entre história e ficção. Segundo o autor:

Fator paralelo, porém de importância capital para a opção pelo composto "narrativas de extração histórica", encontra-se no fato de que o diálogo com a história não se restringe ao âmbito do romance histórico, e sua linha de continuidade, ou ao âmbito das chamadas metaficções historiográficas. Ao contrário, no universo do sistema literário hispano-americano, muito antes do século XIX, já encontramos significativa produção narrativa que toma o histórico como intertexto. (TROUCHE, 2006, p. 43). 


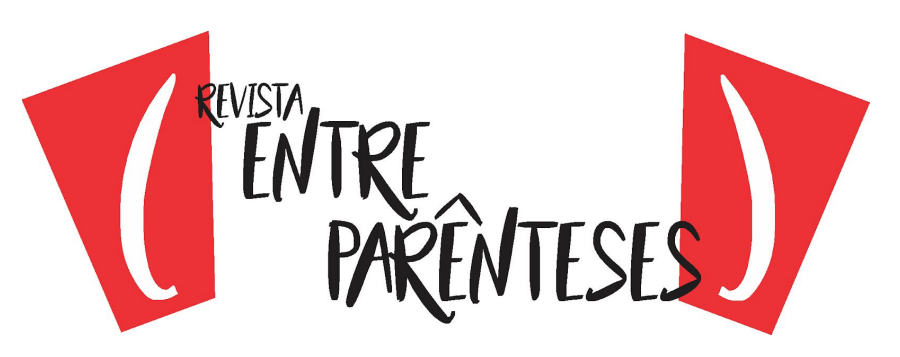

María Rosa Lojo, ao ocupar-se com a releitura da história do passado argentino e com as memórias da Galícia espanhola de onde vieram seus pais - opta por uma modalidade de escrita ficcional híbrida, seja nos contos ou nos romances, cuja estrutura e construção discursiva são frequentes nos representantes do pós-boom latino-americano. Nesse contexto temos obras, cujas narrativas, embora lineares e com uma linguagem bastante próxima do cotidiano do falante hispânico contemporâneo, apresentam uma releitura bastante crítica do passado, alcançada, em especial, pela ótica centrada em personagens antes excluídas, marginalizadas, periféricas ou simplesmente apagadas dos registros oficiais.

Segundo esclarece Fleck (2017), os recursos escriturais utilizados pelos autores desta atual fase das escritas híbridas de história e ficção apresentam-se menos desconstrucionistas e experimentalistas do que aqueles que caracterizam o novo romance histórico latino-americano (paródia, carnavalização, poliperspectivismo, ironia, grotesco, etc). Contudo, essas produções, conforme defende o pesquisador, não deixam de ser críticas frente ao discurso historiográfico tradicional que lançou olhares apenas sobre os homens representativos do poder dominante para consagrá-los heróis e modelos de cidadãos.

Sob esta perspectiva, podemos considerar que a escrita híbrida de María Rosa Lojo é representativa da narrativa classificada por Fleck (2017) como "mediadora", que se posiciona entre a tradição, primeiramente instaurada nas produções clássicas scottianas e as tradicionais que dela logo derivaram, e o criticismo/desconstrucionismo latino-americano de meados do século XX. Narrativas híbridas que, segundo Fleck (2017), não se fixam em "grandes" heróis mitificados pelo discurso historiográfico e na releitura de suas "heróicas" ações para dessacralizá-las, mas buscam por personagens históricas periféricas, marginalizadas, a fim de representar perspectivas negligenciadas pela história oficial. São releituras críticas do passado, mas que evitam o experimentalismo 


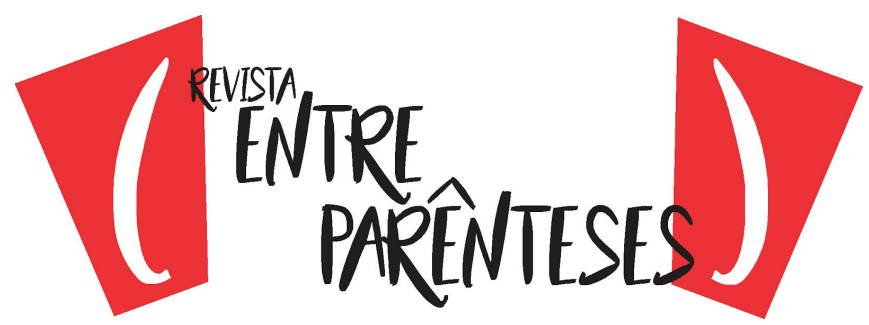

linguístico e formal e relativizam o desconstrucionismo do novo romance histórico e das metaficções historiográficas.

Nas palavras de Esteves (2016), a ficção - que consideramos exemplar das escritas híbridas mediativas descritas por Fleck (2017) - proposta por Lojo

[...] dilui a fronteira dos tempos, ao trazer para o presente o relato das aventuras do passado dele, suscitando leituras plurais, não apenas do passado, como forma de romper discursos totalizantes e hegemônicos, mas também como forma de apresentar aos olhos do presente a possibilidade de ultrapassar limites considerados imutáveis durante muito tempo. (ESTEVES, 2016, p. 74).

A escrita de María Rosa Lojo é, assim, caracterizada pelo rompimento de fronteiras a partir das fissuras do passado e pelas perspectivas excêntricas do que foi registrado como histórico, porém ressignificado por meio do discurso literário. Ela cruza e entrecruza os fios da história e da literatura para marcar, positivamente, as diferenças e as antinomias, responsáveis pela construção da identidade argentina. Como a própria autora afirma: "la asimetría, el desnível [...] es paradigmático en el mestizaje: la relación carnal e cultural que fundara nuestras sociedades coloniales hispano-americanas." (LOJO, 2001, p. 19).

Portanto, a produção literária de María Rosa aborda temáticas da fronteira, do outro, dos limites e da reflexão sobre a identidade argentina. De acordo com o que assinala Esteves (2016), estão presentes, ainda, nas obras de Lojo questões de gênero e o papel da mulher na cultura daquela nação.

$\mathrm{Na}$ análise da narrativa lojiana aqui proposta, a reflexão se dará sob a perspectiva do discurso literário, que se distanciou do histórico apenas no século XIX, divisão essa estabelecida, em parte, pelos princípios filosóficos do positivismo ${ }^{3}$, responsável pela legitimação do discurso historiográfico como hegemônico. No

\footnotetext{
${ }^{3}$ Corrente filosófica surgida na França no começo do século XIX, que teve como principal idealizador Augusto Comte. Defende a ideia de que o único conhecimento tido como válido e verdadeiro é o conhecimento científico.
} 


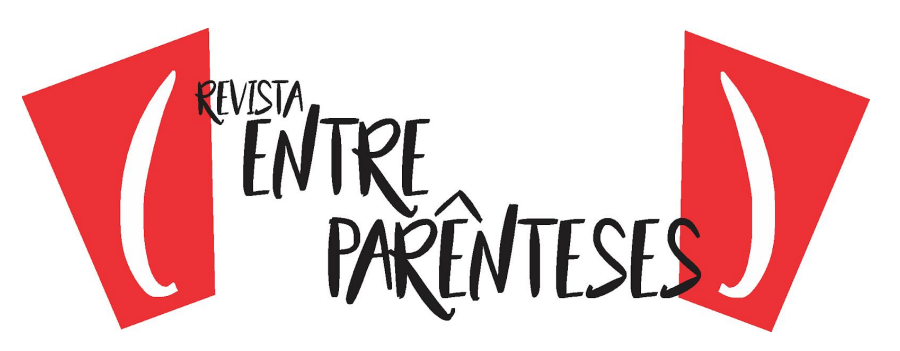

entanto, a partir do relativismo prescrito pela nova história ${ }^{4}$ - que considera atualmente a pluralidade de vozes e não mais apenas a voz monolítica do registro oficial, conforme Fernández Prieto (2003, p. 147) - a partir da década de 70, do século $X X$, as aproximações entre história e literatura se intensificaram.

Nesse cenário, já não cabe ao ficcionista a preocupação com os liames das fronteiras entre os discursos de ambas as áreas, uma vez que a linguagem que produz o discurso, tanto o histórico como o literário, é uma construção linguística e, portanto, é passível de manipulação. Para Esteves e Milton (2007, p. 12), “a memória é frágil e as formas de registrá-la são permeadas pela linguagem e, certamente, pela imaginação."

Assim se dá a construção da escrita híbrida de Lojo, cujo núcleo narrativo está mais centrado em visões excluídas dos registros históricos, para evidenciar perspectivas plausíveis do passado pela ótica de nativos, mulheres, fugitivos, entre outras personagens alijadas dos focos do discurso historiográfico tradicional, do que no desconstrucionismo de grandes heróis e seus feitos.

Neste texto pretendemos analisar, dentre a vasta produção da escritora argentina, a (re)construção da personagem histórica Martina Chapanay (1800-1874), no conto "El Maestro y la Reina de las Amazonas" (LOJO, 2001, p. 127-145), que consideramos exemplar de tudo o que discutimos até aqui sobre a escrita híbrida de Maria Rosa Lojo.

Esse é um dos relatos que compõem a obra Amores insólitos de Nuestra Historia (2001). Essa coletânea de contos foi publicada em 2001, com catorze contos e republicada, em 2011, reunindo dois novos contos: "Té de araucária" e "Muñecas". A obra estrutura-se em três partes: o prólogo - no qual a autora explica o

\footnotetext{
${ }^{4}$ A "nova história", conforme descreve Peter Burke (1992, p. 10), é uma reação em aberta oposição à história tradicional, pois "a nova história é a história escrita como uma reação deliberada contra o paradigma tradicional ou história rankeana". Essa corrente historiográfica atual tem como um dos mais significativos representantes o medievalista francês Jacques Le Goff e retrata uma reação deliberada contra o paradigma tradicional, que considera a visão do senso comum da história como 'a' única maneira de se fazer história, e não 'uma' dentre as várias abordagens possíveis do passado.
} 


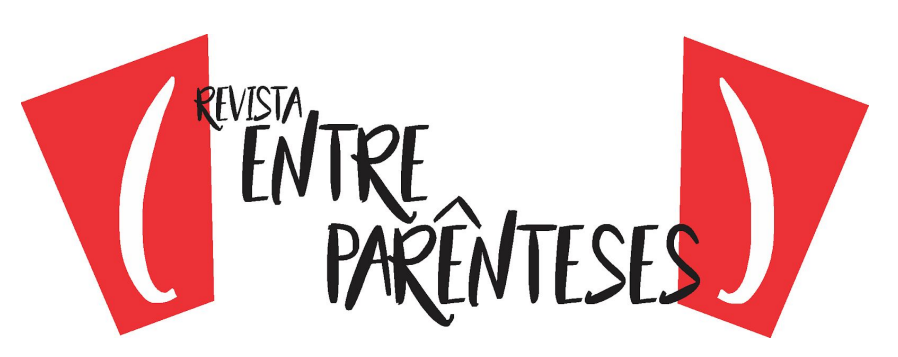

porquê da escolha dos "amores insólitos" como tema e propósito da escrita - que é seguido das narrativas contísticas híbridas de história e ficção e, finalmente, vem o posfácio, no qual constam as bases historiográficas revisadas para composição de cada conto.

O que se evidencia na obra Amores insólitos de Nuestra Historia (2001) são os paradoxos e as contradições que o amor e o poder sempre inspiram ao longo dos séculos, conforme declara a autora no prólogo: "[...] el amor y el poder inspiran las acciones de los dioses y de los hombres, provocan la gloria y la catástrofe, hacen que las vidas mortales merezcan ser contadas [...]." (LOJO, 2001, p. 13). María Rosa Lojo rompe as fronteiras de tempos, espaços, memórias e história e constrói novas possibilidades às personagens históricas, principalmente, àquelas invisibilizadas pelos discurso hegemônico.

Este é o contexto em que se situa a obra Amores Insólitos de Nuestra Historia (2001), composta por relatos que contam os amores incomuns de personagens que transgrediram a ordem 'natural' das convenções sociais, personagens essas que habitam os livros de história da Argentina ou que foram ignoradas pela historiografia.

Munida da possibilidade que o discurso literário lhe concede de revisitar o passado e contestar a perspectiva única dos fatos registrados pela história oficializada, a autora oferece ao leitor um novo olhar à Argentina do século XIX e reconstrói personagens históricas, reposicionando-as dentro de uma hierarquia que parecia inabalável. Para tal, a autora emprega a liberdade que a literatura lhe oferece, conforme afirma Fleck (2013), concedendo, assim, ao leitor, revisitar a história, reinterpretá-la, reescrevê-la.

Quanto à gênese do conto destacado, a autora relata que essa surgiu de uma nota de rodapé na obra Juan Facundo Quiroga, de David Peña, de 1906, na 


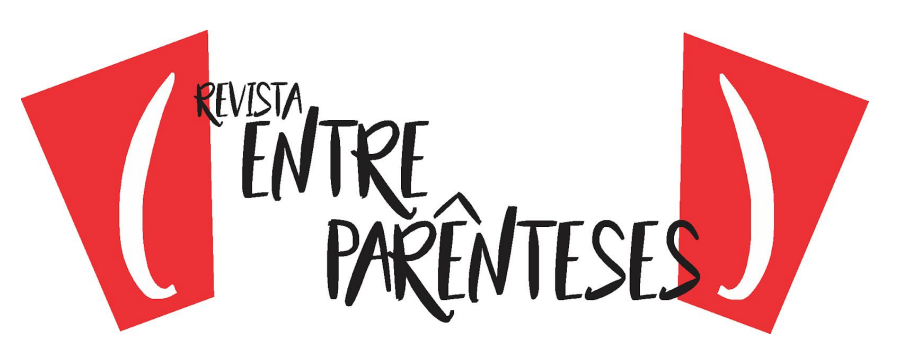

qual o autor busca produzir uma biografia revisionista do Tigre de los Llanos ${ }^{5}$, a fim de outorgar à personagem histórica parte de sua humanidade que havia sido invisiblizada pela história difundida por Sarmiento ${ }^{6}$. Tal desejo, já em evidência no século $X X$, foi acrescido, no início do século XXI, pelo de María Rosa de propor uma escrita poética sobre os "amores insólitos" da sociedade argentina, responsáveis por boa parte da construção identitária da nação que se configurou, embora seja um fato nem sempre aceito, pela mestiçagem e aliança das culturas e etnias.

\section{O CONTO: "EL MAESTRO Y LA REINA DE LAS AMAZONAS": ANTÍTESE DA FIGURA FEMININA RESSIGNIFICADA PELA FICÇÃO DE MARÍA ROSA LOJO}

$\mathrm{Na}$ organização linear proposta pela autora, o conto "El Maestro y la Reina de las Amazonas" é o sexto relato que compõe a estrutura da obra Amores Insólitos de Nuestra História (2001). A relação entre um professor e uma guerrilheira que atuou nas guerras civis argentinas do século XIX é o que outorga a perspectiva de insólito ao conto. A narrativa relata a história do sequestro de um professor, tramado por Martina Chapanay (1800-1874), personagem de extração histórica, revisitada no discurso literário de María Rosa Lojo.

Martina Chapanay (Valle del Zonda/Mogna), filha de um cacique huarpe Ambrosio Chapanay e uma criolla - Mercedez González, foi casada com um montonero de Quiroga e lutou no conflito entre unitários e federalistas. De acordo com a biografia de Marcos Estrada, Martina Chapanay, realidad y mito (1962), depois da morte do seu companheiro e de Quiroga, a personagem lendária tornou-se uma famosa bandoleira que roubava dos ricos e distribuía o saque entre

\footnotetext{
5 Juan Facundo Quiroga (1788-1835), caudilho argentino, militar, político e defensor do Federalismo (Confederação Argentina), ficou conhecido como "Tigre de los Llanos" por matar um puma quando criança.

${ }^{6}$ Domingo Faustino Sarmiento (1811-1888), jornalista, escritor e Presidente da Argentina. Durante seu exílio no Chile, devido a sua objeção ao regime de Juan Manuel Rosas (governador de Buenos Aires e líder do Partido Federal), escreveu seu livro mais famoso "Facundo o Civilización y Barbarie" (1845), uma biografia do caudilho argentino Facundo Quiroga.
} 


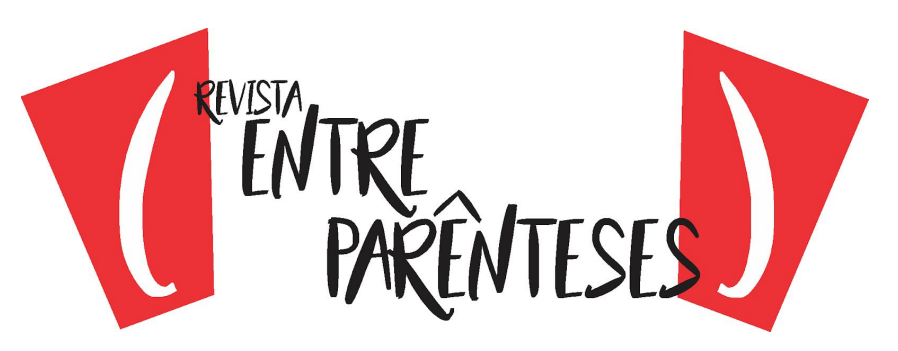

os pobres - um arquétipo feminino de Robin Hood.

É descrita como uma mulher forte que não se cansava com o trabalho pesado. Usava trajes masculinos e gostava das tarefas masculinas, pois "no le fatigaban los viajes ni el trabajo incesante, aguantaba sin quejas el frío, el calor o el sufrimiento físico." (ESTRADA, 1962). Sem dúvida, sua personalidade contrapunha-se ao modelo patriarcal dominante do século XIX quanto à postura esperada para uma jovem. Nas palavras de Fanchin (2014, p. 126), vemos que

[...] sin lugar a dudas, Martina era la antítesis del ideal femenino por sus comportamientos admitidos como varoniles, completamente ajenos al encierro doméstico. Debido a que representaba el contra modelo en el nuevo orden decimonónico, la narrativa escrita, aunque intenta disimular o al menos mostrar una reconversión al final de su días - no logra ocultar las versiones que transitan oralmente, y es que fue una mujer independiente.

A personagem histórica, Martina Chapanay carrega o protótipo de "bandolera y montonera" e alcançou popularidade na região de Cuyo, devido a sua coragem e participação nas guerras civis acrescidas ao seu convívio com os homens nas campañas, passou a formar parte do imaginário coletivo da nação argentina (FACHIN, 2014). No conto selecionado, a figura da guerrilheira é resgatada pela autora María Rosa Lojo, que lhe concede um lugar de enunciação, no qual a história pode ser recontada sob a perspectiva de uma combatente que esteve junto a renomadas personagens como Facundo Quiroga e Chaco Peñaloza ${ }^{7}$, representantes notórios dos sangrentos conflitos entre federalistas e unitários que caracterizam as primeiras décadas de uma Argentina independente.

O conto está dividido em duas partes: a primeira intitulada: Pueblo Viejo y Pie de Palo, 1850, relata a chegada de um 'gaucho' a uma escola em Pueblo Viejo.

\footnotetext{
7 Ángel Vicente Peñaloza (1797-1863) - militar argentino (La Rioja), conhecido como "El Chaco", esteve sob o comando de Juan Facundo Quiroga, foi atuante em muitas ações com o propósito de organizar a Argentina e acabar com as lutas oriundas das Guerras Civis.
} 


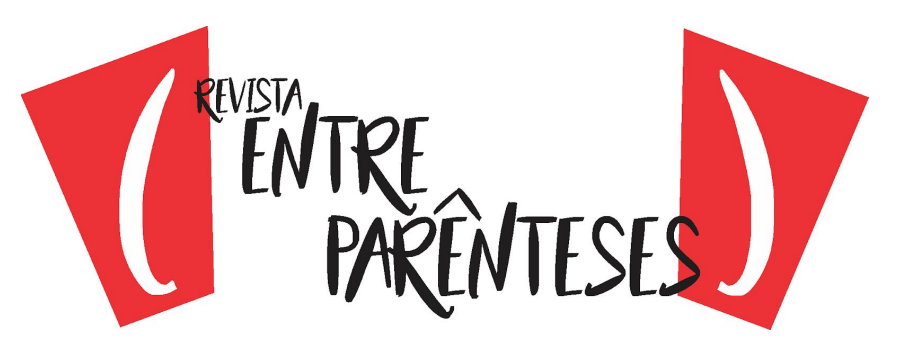

O foco narrativo da diegese é a do professor que descreve como se deu a aproximação do 'estranho' a sua classe e de como descobriu que se tratava de uma mulher:

A medida que me acercaba, iba notando algo raro, fuera de lo previsible, en ese jinete vestido como gaucho en día de fiesta. Como yo no llevaba sombrero, lo saludé con una inclinación. Pero él, que sí iba con el chambergo puesto, se lo quitó en un golpe de sorpresa para que le cayeran sobre los hombros dos trenzas negras. Me sonrió entonces. [...] aprecié los ojos garzos incompatibles con el color de la piel, y la boca grande y llena que se le dibujaba sola, sin ayuda alguna del carmín de Chile. (LOJO), 2001, p. 130).

Durante uma semana a moça observa o professor em suas aulas e é o padre da cidade quem Ihe informa sobre a montonera de Facundo, Martina Chapanay. O professor precisa fazer uma viagem para resolver alguns trâmites sobre uma herança. No percurso da viagem é atacado e ameaçado com uma faca pela própria Martina, que o sequestra.

O motivo que a levou a sequestrá-lo é desconhecido pelo professor, pois ela sabia que ele não possuía dinheiro e que também nunca a havia ofendido. Depois de uma noite após o sequestro, Martina revela ao professor a razão de sua atitude, quer que ele a ensine a ler e a escrever e deseja que isso não seja razão para chacota, caso soubessem dessa sua fragilidade.

O relato passa, então, a ser contado, sob a perspectiva do professor, no qual ele narra como Martina Chapanay se dedicava e aprendia com rapidez, como se observa em:

Leer me parece mucho más sencillo que rastrear. Imagínese: si a mí me basta ver unas gotas de agua sobre el pasto, o la manera en que se han quebrado unas ramas, para saber cuántos hombres pasaron por una senda, con qué carga, con qué cabalgadura, y hace cuánto tiempo, ¿cómo no voy a entender lo que quieren decir cuatro letras juntas? (LOJO, 2001, p. 137-138). 


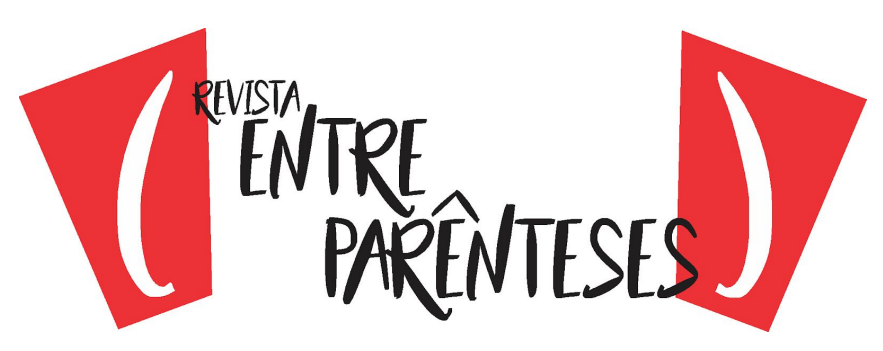

Em meio às aulas que se seguiam, o professor reflete sobre seus alunos que ficaram sem seu maestro e, também, no advogado que o esperava e decide, pois, questionar a Martina sobre Facundo Quiroga, para saber se suas ações de valentia foram válidas. Chapanay o surpreende, dizendo que sua luta foi pela sua terra e liberdade do seu povo e não por Quiroga. As aulas do professor são finalizadas com a leitura do livro de Sarmiento: Facundo o Civilización y barbárie (1845).

É neste momento do conto que, por meio dos questionamentos de Martina sobre a história contada por Sarmiento, María Rosa dá voz aos que foram esquecidos pelo discurso hegemônico, pois a personagem da narrativa faz consideráveis emendas, correções e alterações aos registros do caudilho.

Su señor Sarmiento a veces parece una vieja contando chismes, y suele equivocarse fiero, de medio a medio. Casi no acierta una, ni siquiera cuando dijo que Facundo vivía corriendo tras las hembras bonitas. Eran más las que a él le tenían echado el ojo, tanto por su fama como por su fortuna. [...] Sí el señor Sarmiento me hubiera conocido - apuntaba Martina - podía haber puesto los tres capítulos en uno. Tanto he guiado tropas, como he buscado hombres $y$ animales, y también los he robado. Claro que si me hubiera mentado a mí quizá ni los porteños ni los gringos le hubiesen creído. Nadie supone que las mujeres hagan esas cosas. (LOJO, 2001, p. 139-140).

Dessa maneira, María Rosa Lojo aponta a possibilidade de Sarmineto desconhecer ou desconsiderar a participação das mulheres nas guerras, uma vez que Martina reclama da ausência do seu nome no livro Facundo o Civilización y barbárie. Neste momento do conto, o professor reflete sobre as ações de Martina e a compara às amazonas.

A segunda parte da narrativa, intitulada Jáchal, 1880, ambienta-se na cidade em que está sepultada Martina, local muito visitado e onde são levados 


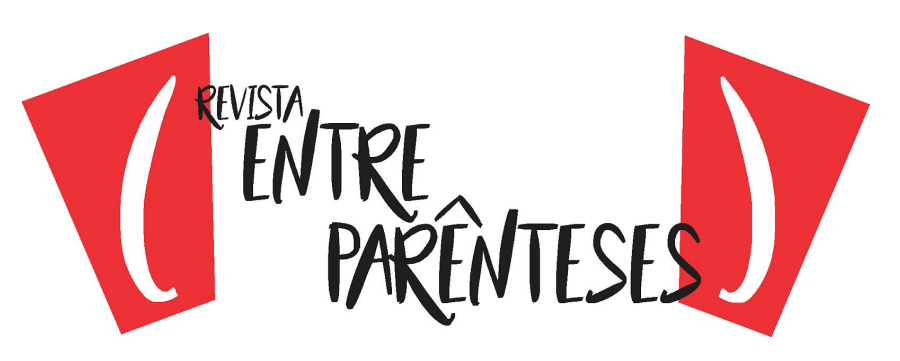

muitos doces e bebidas. De acordo com o narrador do conto, depois que Martina Chapanay conseguiu realizar seu propósito, ela voltou para Vale Fértil, onde começou a ajudar a população doente com as suas ervas, como se constata em: "Dicen que siguió rastreando hacienda extraviada, y que ayudaba a los viajeros a cruzar los vados peligrosos. [...] Que, como sus antepasados huarpes, curaba com yerbas [...]." (LOJO, 2001, p. 144).

Quanto ao professor, casou-se, teve seis filhos e, no momento relatado, visita a lápide de Martina Chapanay, onde reflete sobre como teria sido sua vida se tivesse acompanhado a heroína argentina, pois, para ele, as proezas de Martina são incomparáveis, como se observa no fragmento: “¿Qué podría yo contarle a cambio? Al lado de sus hechos, cuanto me ha sucedido parece trivial, muy poca cosa." (LOJO, 2001, p. 144).

Como é de costume, no local da sepultura de Martina, ele leva aguardente e, embriagando-se, mantém a esperança de reencontrar a mulher, que para ele era mais bela que a Rainha das Amazonas.

\section{CONSIDERAÇÕES FINAIS}

O conto comentado resgata a figura fascinante e tão pouco conhecida, como de tantas outras mulheres combatentes, da sanjuanina Martina Chapanay e, de acordo com Lojo (2001), são verídicas todas as habilidades que se enumeram no conto com referência à personagem histórica.

O processo de reconstrução da personagem ao longo da produção literária é evidente quando Martina aponta distorções no texto de Sarmiento, o que indica a visão da escritora sobre a história oficial, que está sob perspectivas singulares. Martina Chapanay é apresentada no relato como uma mulher que se dá conta do seu apagamento na memória cumulativa - por isso Ihe aflige a necessidade de aprender a ler e escrever, habilidades essas essenciais aos registros da história, 


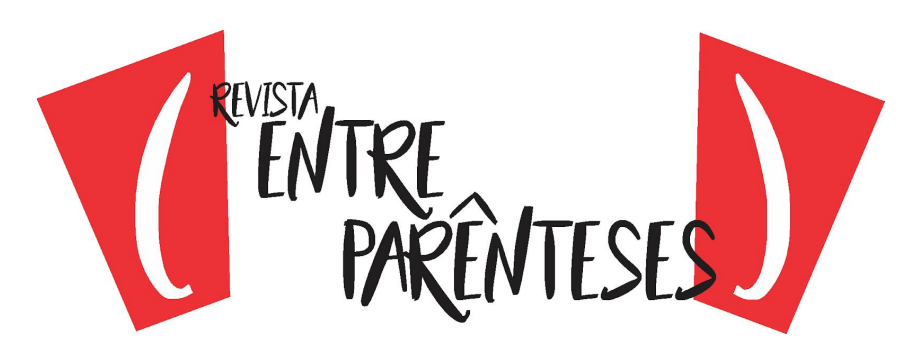

uma vez que a personagem percebe o privilégio extracognitivo que a leitura e a escrita têm sobre outros saberes que, segundo ela, são bem mais complexos.

Não há referência no conto da mensuração do tempo em que o professor esteve preso, apenas do período entre a primeira e a segunda parte da narrativa. No entanto, segundo Coelho (2015), há ainda uma terceira parte do conto, constituída pela lacuna de 30 anos entre a última vez que o professor viu Martina e o momento em que está no túmulo dela, rememorando o acontecido - simbolicamente a sua inexistência representa a inutilidade da vida escolhida pelo maestro diante da significativa participação de Martina nos conflitos do desejo de independência da nação argentina.

Para Coelho (2015), nas entrelinhas do texto é que estão imbrincados os conflitos entre unitários e federalistas, entre Buenos Aires e San Juan, entre Sarmiento e Quiroga, e, por extensão, entre o mundo do professor e o da rainha das Amazonas, embora esteja presente na história o registro da incapacidade dos portenhos em admitir que uma mulher - Martina Chapanay - protagonizou este conflito.

O conto, de acordo com o posfácio do livro de Lojo (2001), inspira-se na narrativa de Marcos Estrada (1962) - Martina Chapanay: realidad y mito, segundo a qual, a personagem em sua época de bandoleira havia estado em Pueblo Viejo para apoderar-se de um jovem que a agradava. De acordo também com o biógrafo Pedro Echagüe (1884), Martina tinha uma especial curiosidade em aprender a ler e a escrever, Lojo uniu, então, o encontro amoroso com a vontade da aprendizagem.

A narrativa de Lojo faz uma analogia de Chapanay às míticas amazonas que, como a personagem histórica, despertaram temor, mas ficaram na memória americana como lendas distantes, as quais - independentemente de serem elas personagens reais ou construções ressignificadas pela literatura - simbolizam a insurreição contra o paradigma dominante da história oficial, como mulheres e guerrilheiras. 


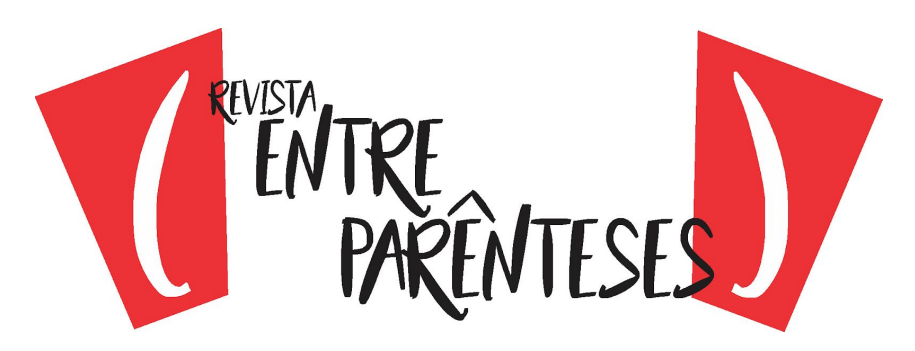

\section{Referências}

AíNSA, Fernando. La nueva novela histórica latinoamericana. Plural (México), n. 240, p.28-85, 1991.

COELHO, Maria Josele Bucco. Mobilidades culturais na contista rio-platense de autoria feminina: tracejando as poéticas da distância em Josefina Plá e María Rosa Lojo. 2015. 200 f. Tese (Doutorado em Letras) - Curso de Letras, Universidade Federal do Rio Grande do Sul, Porto Alegre, 2015.

ECHAGÜE, Pedro. "La Chapanay. Novela-Tradición”, Memorias y Tradiciones, Buenos Aires, 1884.

ESTRADA, Marcos, Martina Chapanay. Realidad y mito, Buenos Aires, Imprensa Varese, 1962.

ESTEVES, Antônio Roberto. Outras caras do poder: uma leitura de "Amar a un hombre feo", de María Rosa Lojo. In: RAPUCCI, C. A.; CARLOS, A.M. (Orgs). Cultura e representação: ensaios. Assis: Triunfal Gráfica e Editora, 2011.

História e Memória em María Rosa Lojo (Tributo a Marilene Weinhardt). Rev. Letras, Curitiba, n. 96, p. 69-87, jun/dez 2016.

ESTEVES, Antônio Roberto; MILTON, Heloisa Costa. Narrativas de extração histórica. In: CARLOS, A. M.; ESTEVES, A. R. (Org.). Ficção e história: leitura de romances contemporâneos. Assis: FCL-UNESP, 2007. p. 9-28.

FANCHIN, Ana Teresa. Martina Chapanay en la Construcción Literaria y en el Imaginario Popular. Revista dos Puntas, San Juan, v. 6, n. 10, p.115-128, out. 2014.

FLECK, Gilmei Francisco. A conquista do "entre-Iugar": a trajetória do romance histórico na América. In: Gragoatá, n. 23, segundo semestre. Niterói: EDUFF, 2007. p. 149-167.

Gêneros híbridos da contemporaneidade: o romance histórico contemporâneo de mediação. In: RAPUCCI, Cleide A.; CARLOS, Ana Maria (Org.). Cultura e representação: ensaios. Assis: Triunfal Gráfica e Editora, 2011. p. 81-93. 


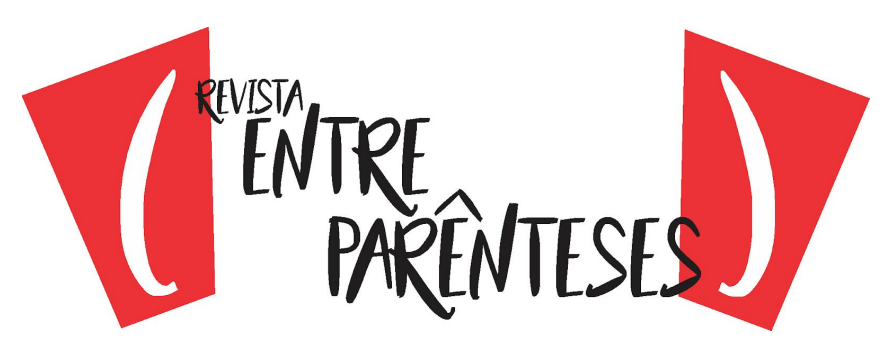

O processo de leitura do romance histórico: confluências de perspectivas e discursos. In: $16^{a}$ Jornada de Estudos Linguísticos e Literários, 16. 2013, Marechal Cândido Rondon. Anais.... Marechal Cândido Rondon: Unioeste, 2013. p. 1-8.

. O romance histórico contemporâneo de mediação: entre a tradição e o desconstrucionismo - leituras críticas da história pela ficção. Curitiba, CRV, 2017.

LARIOS, Marco Aurelio. Espejo de dos rostros. Modernidad y postmodernidad em tratamiento de la historia. In: KOHUT, K. (Ed.). La invención del pasado: la novela histórica en el marco de la posmodernidad. Franfurt; Madrid: Vervuert, 1997. P. 130-136.

LOJO, María Rosa. Amores insólitos de nuestra historia. 1. ed. Buenos Aires, Aguilar, 2001.

. Mínima autobiografía de una "exiliada hija". L'exili literari republicà. Edició a cura de Manuel Fuentes y Paco Tovar. Tarragona, URV, 2006, p.87-97. Disponível em: http://www.mariarosalojo.com.ar/acerca/index.htm. Acesso em: 01 jul. 2018.

PAPESCHI, Muryel da Silva. Juan Facundo Quiroga: um homem, vários personagens. 2014. $121 \mathrm{f}$. Dissertação (Mestrado em Letras) - Curso de Letras, Universidade Estadual Paulista, Assis, 2014.

PRIETO, Celia Fernández. Historia y novela: poética de la novela histórica. 2. ed. Navarra: Universidad de Navarra, 2003.

SANTIAGO, Silviano. Uma literatura nos trópicos. Rio de Janeiro, Rocco, 2000.

TROUCHE, André Luiz. Gonçalves. América: história e ficção. Niterói: Ed. UFF, 2006.

Recebido em 18/07/2018

Aceito em 28/08/2018 